SPIE's $12^{\text {th }}$ International Symposium on Smart Structures and Materials and $10^{\text {th }}$ International Symposium on

NDE for Health Monitoring and Diagnostics, Smart Structures and Integrated Systems Conference, San Diego, CA, 7-10 March, 2005, paper \# 5764-59

\title{
Development of Specifications for an Integrated Piezoelectric Wafer Active Sensors System
}

\author{
Christopher Jenkins, Victor Giurgiutiu, Bin Lin, Weiping Liu \\ Mechanical Engineering Department, University of South Carolina \\ Columbia, SC 29208
}

\begin{abstract}
This paper describes work performed in the development of a set of specification for the construction of an integrated electronic system for piezoelectric wafer active sensor (PWAS). The paper starts with a comprehensive review of the PWAS material properties, dimensions, and electrical characteristics. PWAS of various shapes and sizes are considered. Two boundary conditions were examined: free PWAS and PWAS attached to actual structures. For both, the PWAS immittance and the allowable dc and ac voltages were considered. The predicted values were compared with measurements performed over a wide frequency range (10 kHz to $2 \mathrm{MHz})$.

Next, the electronic-equipment specifications were considered. The PWAS can be used in a number of different ways to actively detect damage in structures. Our aim was to develop electronic-equipment specifications that would extract the optimum performance from the PWAS, i.e., maximize the coupling with the structure and obtain large-amplitude Lamb wave transmission and reception. Analytical predictions were compared with measurements made using current laboratory equipment. The comparative analysis revealed that the current electronic equipment does not fully exploit the PWAS capabilities. Hence, the PWAS equipment specifications were divided into two categories: "existing" and "desired". The former category designates integrated electronic equipment that would offer the same PWAS performance as the existing lab equipment, but be of a lower volume/weight/cost. The latter category refers to advanced electronic equipment that will exploit the full potential of PWAS transducers while being of lower volume/weight/cost than the lab equipment. Both categories are presented and discussed in the paper.
\end{abstract}

Keywords: structural health monitoring, piezoelectric wafer active sensor, envelope extraction, nondestructive evaluation, piezoelectric, damage detection, cracks, ultrasonic, Lamb waves, SHM, PWAS, NDE

\section{INTRODUCTION}

Embedded nondestructive evaluation (NDE) is an emerging technology that will allow transitioning the methods of conventional ultrasonic to embedded systems for structural health monitoring (SHM). SHM requires the development of small, lightweight, inexpensive, unobtrusive, minimally invasive sensors to be embedded in the structure with minimum weight penalty and at affordable costs. Such sensors should be able to scan the structure and identify the presence of defects and incipient damage.

Current ultrasonic inspection of thin wall structures (e.g., aircraft shells, storage tanks, large pipes, etc.) is a time consuming operation that requires meticulous through-the-thickness C-scans over large areas. One method to increase the efficiency of thin-wall structures inspection is to utilize guided waves (e.g., Lamb waves) instead of the conventional pressure and shear waves. Guided waves propagate along the surface of thin-wall plates and shallow shells. They can travel at relatively large distances with very little amplitude loss and offer the advantage of large-area coverage with a minimum of installed sensors. Guided Lamb waves have opened new opportunities for cost-effective detection of damage in aircraft structures. Traditionally, guided waves have been generated by impinging the plate obliquely with a tone-burst from a relatively large ultrasonic transducer. Snell's law ensures mode conversion at the interface, hence a combination of pressure and shear waves are simultaneously generated into the thin plate. However, conventional Lambwave probes (wedge and comb transducers) are relatively too heavy and expensive to be considered for widespread deployment on an aircraft structure as part of a SHM system. Hence, a different type of sensors than the conventional ultrasonic transducers is required for the SHM systems.

\section{PIEZOELECTRIC WAFER ACTIVE SENSORS}

Guided waves can be excited and detected with a variety of methods. In conventional ultrasonics, guided waves are generated by impinging the structural surface obliquely with an ultrasonic beam from a relatively large ultrasonic transducer affixed to a wedge. Snell's law ensures mode conversion at the interface, hence a combination of pressure and 
shear waves are simultaneously generated into the structure. If the structure is thin walled, guided waves are being created. Another method of creating guided waves in a structure is by using a comb transducer. The comb spacing is such that it tunes with the guided wave half wavelength. However, conventional Lamb-wave probes (wedge and comb transducers) are relatively too heavy and expensive to be considered for widespread deployment on an aircraft structure as part of an active SHM system. A typical wedge transducer weighs 25 grams, costs $\sim \$ 400$, and is 40 -mm tall (Figure 1a). Conventional ultrasonic transducers are inappropriate for active SHM applications due to their cost, weight, and size. Conventional ultrasonic transducers could not be embedded in large numbers into a structure without incurring important cost and weight penalties.

(a)

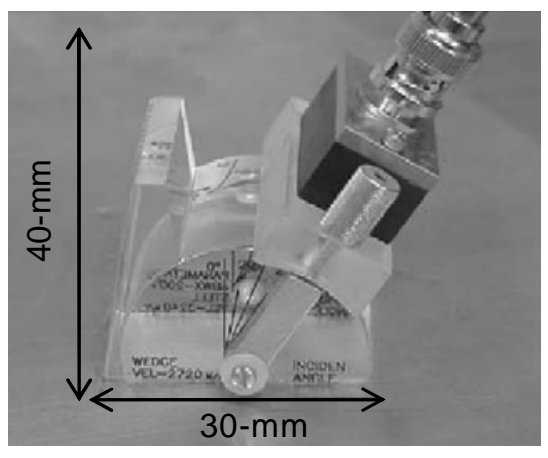

(b)

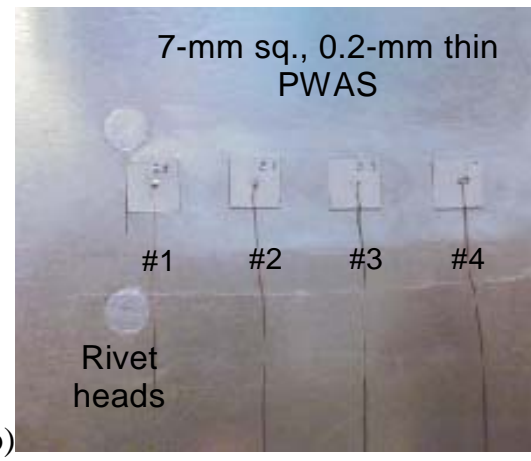

Figure 1: (a) conventional Lamb wave ultrasonic transducer ( $\sim 25$ grams, $\sim \$ 400,40-\mathrm{mm}$ tall); (b) piezoelectric wafer active sensors (PWAS): 0.08 grams, $\$ 15,0.2 \mathrm{~mm}$ thin

An automated structural health monitoring system embedded into the aircraft structure is not possible using conventional ultrasonic transducers. For such a system, the sensors must be as much as possible part of the structure on which they are attached. Hence, active sensors that are different from the conventional ultrasonic transducers are required. New types of Lamb-wave transducers must be developed; they must be small, light weight, unobtrusive, and low cost. They should be embedded in the airframe with minimum weight penalty and at affordable costs. In recent years, piezoelectric wafers permanently attached to the structure have been extensively used for the generation and detection of guided waves. These simple devices are inexpensive, lightweight, and unobtrusive (Figure 1b). They seem well suited for structural health monitoring applications. They can act as both transmitters and receivers of ultrasonic waves. For lack of a better term, Giurgiutiu et al. (2000) called these embedded transducers piezoelectric wafer active sensors (PWAS). Typical PWAS weigh around $68 \mathrm{mg}$, are $0.2 \mathrm{~mm}$ thick, and cost $\sim \$ 15$ each. Giurgiutiu and Zagrai (2000) characterized the PWAS for structural health monitoring and developed quality assurance techniques. Lamb-wave NDE techniques are being transitioned to embedded applications using PWAS technology.

PWAS operates on the piezoelectric principle that couples the electrical and mechanical variables in the material (mechanical strain, $S_{i j}$, mechanical stress, $T_{k l}$, electrical field, $E_{k}$, and electrical displacement $D_{j}$ ) in the form:

$$
\begin{aligned}
& S_{i j}=s_{i j k l}^{E} T_{k l}+d_{k i j} E_{k} \\
& D_{j}=d_{j k l} T_{k l}+\varepsilon_{j k}^{T} E_{k}
\end{aligned}
$$

where $s_{i j k l}^{E}$ is the mechanical compliance of the material measured at zero electric field $(E=0), \varepsilon_{j k}^{T}$ is the dielectric permittivity measured at zero mechanical stress $(T=0)$, and $d_{k i j}$ represents the piezoelectric coupling effect. The direct piezoelectric effect converts the stress applied to the sensor into electric charge. Similarly, the converse piezoelectric effect produces strain when a voltage is applied to the sensor. For embedded NDE applications, PWAS couple their inplane motion, electrically excited through the piezoelectric effect, with the Lamb-waves particle motion on the material surface. Lamb waves can be either quasi-axial $\left(S_{0}, S_{1}, S_{2}, \ldots\right)$, or quasi-flexural $\left(A_{0}, A_{1}, A_{2}, \ldots\right)$. PWAS transducers can act as both exciters and detectors of the elastic Lamb waves traveling in the material. PWAS can be used as both active and passive probes and thus can address four SHM needs:

1. Active sensing of far-field damage using pulse-echo, pitch-catch, and phased-array methods

2. Active sensing of near-field damage using high-frequency impedance method

3. Passive sensing of crack initiation and growth through acoustic emission

4. Passive sensing of damage-generating events through low-velocity impact detection

This indicates that the PWAS transducers are strong candidates for active SHM applications. 


\section{SPECIFICATION FOR PIEZOELECTRIC WAFERS ACTIVE SENSORS (PWAS)}

\subsection{PWAS Specifications Overview:}

The operating voltage range of the PWAS is $-30 \mathrm{~V}$ to $120 \mathrm{~V}$ with DC bias of $V_{D C}=45 \mathrm{~V}$ and an amplitude of $V_{a}=75 V(V(t)=45 \pm 75 V)$. The existing PWAS are a 7-mm sq PWAS and a 7-mm diameter PWAS. The desired PWAS are a 10-mm sq PWAS and a 10-mm diameter PWAS. Both the existing and desired PWAS have a thickness of $0.2 \mathrm{~mm}$. The theoretical free capacitances are: 7-mm sq PWAS $C=3.79 \mathrm{nF} ; 7-\mathrm{mm}$ diameter PWAS $C=2.98 \mathrm{nF}$; 10 -mm sq PWAS $C=7.74 \mathrm{nF}$; and $10-\mathrm{mm}$ diameter PWAS $C=6.08 \mathrm{nF}$. The PWAS operating frequency range is $10 \mathrm{kHz}$ to $2,000 \mathrm{kHz}$.

\subsection{PWAS Voltage Range}

American Piezo Corporation, the current supplier of PWAS materials, specifies voltage limitations according to the composition and thickness of the material. Some of these voltage limitations are listed in the table below. VDC corresponds to DC voltage. VAC corresponds to an unbiased AC voltage measured from peak to peak. Table 1 shows the VDC and VAC for various piezoelectric materials. We are using the APC 850.

Table 1 VDC and VAC of APC Material

\begin{tabular}{|l|l|l|}
\hline Material & VDC & \multicolumn{1}{|l|}{$\begin{array}{c}\text { VAC (peak to peak) } \\
\text { No Bias }\end{array}$} \\
\hline APC 850 & $15 \mathrm{~V} / \mathrm{mil}$ & $8 \mathrm{~V} / \mathrm{mil}$ \\
\hline APC $850 \mathrm{~B}$ & $11 \mathrm{~V} / \mathrm{mil}$ & $6 \mathrm{~V} / \mathrm{mil}$ \\
\hline APC 855 & $10 \mathrm{~V} / \mathrm{mil}$ & $5 \mathrm{~V} / \mathrm{mil}$ \\
\hline APC 840 & $18 \mathrm{~V} / \mathrm{mil}$ & $9 \mathrm{~V} / \mathrm{mil}$ \\
\hline APC 880 & $20 \mathrm{~V} / \mathrm{mil}$ & $10 \mathrm{~V} / \mathrm{mil}$ \\
\hline
\end{tabular}

Table 1 indicates that APC 850 can withstand $-4 \mathrm{~V} /$ mil reverse bias and $+15 \mathrm{~V} / \mathrm{mil}$ direct bias. The actual voltage limits for a $0.2 \mathrm{~mm}$ thick wafer are:

$$
\begin{aligned}
& V_{\text {min }}=-4 \frac{\mathrm{V}}{\mathrm{mil}} \times \frac{1 \mathrm{mil}}{0.0254 \mathrm{~mm}} \times 0.2 \mathrm{~mm} \cong-30 \mathrm{~V} \\
& V_{\max }=15 \frac{\mathrm{V}}{\mathrm{mil}} \times \frac{1 \mathrm{mil}}{0.0254 \mathrm{~mm}} \times 0.2 \mathrm{~mm} \cong 120 \mathrm{~V}
\end{aligned}
$$

The maximum dynamic excitation with DC bias that can be applied to the PWAS is: $V(t)=45 \pm 75 \mathrm{~V}$, i.e. a DC bias $V_{D C}=45 \mathrm{~V}$ and an AC amplitude of $V_{a}=75 \mathrm{~V}$.

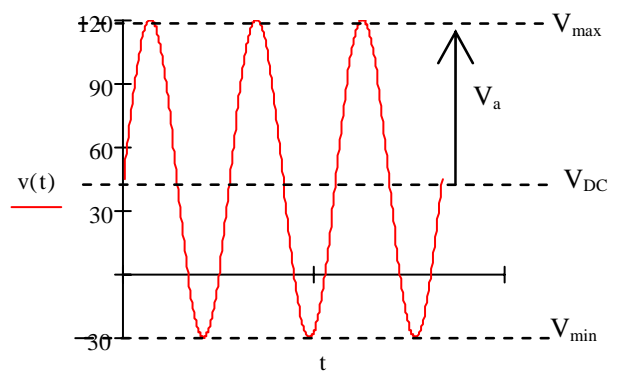

Figure 2 Graph of $V(t)=45 \pm 75 \mathrm{~V}$ with $V_{D C}=45 \mathrm{~V}, V_{a}=75 \mathrm{~V}, V_{\max }=120 \mathrm{~V}$, and $V_{\min }=-30 \mathrm{~V}$ 


\subsection{Quality-Controlled PWAS Fabrication Method}

We have developed a quality-controlled PWAS fabrication method that ensures consistent results with narrow statistical spread. PWAS fabrication starts with small size piezoelectric wafers, which are first equipped with minute terminals, and then applied to the structure through a rigorously controlled procedure. PWAS quality control consists in a very careful measurement and recording of the PWAS geometrical, mechanical, electrical, and electromechanical properties; the sorting of PWAS in tightly controlled classes of intrinsic properties; and the monitoring of these properties through the fabrication process and the installation procedure. Initial efforts by the author have indicated that a rigorous fabrication and quality control methodology is needed to assure that PWAS present a consistent intrinsic behavior. In order to save costs, early efforts attempted to fabricate the small 6-mm sq. sensors out of large PZT sheet using conventional tooling. This process, though inexpensive, was producing significant variation in sensor size and geometry that affected its electromechanical $(\mathrm{E} / \mathrm{M})$ readings. In order to reduce uncertainties, we identified vendors of small-size piezoelectric wafers, produced with precision technologies. The small PZT wafers produced by American Piezo Ceramics, Inc. were selected based on their low cost and good manufacturing tolerances (Table 2).

Table 2 Comparison of potential providers of piezoelectric wafers

\begin{tabular}{|l|l|l|l|l|l|l|l|l|}
\hline & APC & \multicolumn{3}{l}{ STEMINC } & \multicolumn{2}{l}{ Piezo systems } & Staveley \\
\hline & 850 & SM-D & SM-K & SM-QA & SM-QB & A4 & H4 & \\
\hline d31 & -175 & -320 & -210 & -150 & -160 & -190 & -320 & -173 \\
\hline d33 & 400 & 650 & 450 & 320 & 330 & 390 & 650 & 380 \\
\hline price of round & $\$ 1.74$ & $\$ 0.3$ & & $\$ 2.09$ & $\$ 5.7$ \\
\hline price of square & $\$ 1.88$ & $\$ 0.3$ & & $\$ 1.44$ & $\$ 7$ \\
\hline Setup fee & 0 & $\$ 192$ & & 0 & 0 \\
\hline Ship date & 4 weeks & & & $4-5$ weeks & 6 weeks \\
\hline
\end{tabular}

The selected provider is APC International, Ltd, the selected material is Lead Zirconium Titanium (PZT) APC 850, and the selected geometries are P $7.00 \mathrm{~mm}$ X $7.00 \mathrm{~mm}$ X $0.20 \mathrm{~mm}$ and D $7.00 \mathrm{~mm}$ X $0.20 \mathrm{~mm}$.

\subsection{Quality Control Methodology}

Twenty-five APC-850 piezoelectric wafers ( $7 \mathrm{~mm}$ sq., $0.2 \mathrm{~mm}$ thick, silver electrodes on both sides) were acquired and subjected to statistical evaluation. In this process, we started with the mechanical and electrical properties declared by the vendor and then conducted our own measurements to verify the vendor data and evaluate its integrity. The mechanical tolerances of these wafers, as presented by the vendor on their website, are given in Table 3 . The material properties of the basic PZT material are given in Table 4. The tolerances declared by the vendor for some standard electrical properties were $\pm 5 \%$ in resonance frequency, $\pm 20 \%$ in capacitance and $\pm 20 \%$ in the $d_{33}$ constant. Standardized test methods for in process quality assurance of active sensor fabrication process were developed based on the following measurements: Geometrical dimensions, Electrical capacitance, and Electromechanical (E/M) impedance and admittance

Table 3 Manufacturing tolerances for APC, Inc. small piezoelectric wafers (www.americanpiezo.com )

\begin{tabular}{|c|c|c|}
\hline Dimension & Units $(\mathrm{mm})$ & Standard Tolerance \\
\hline Length or Width of Plates & $<13 \mathrm{~mm}$ & $+/-0.13 \mathrm{~mm}$ \\
\hline Thickness of All Parts & $0.20 \mathrm{~mm}$ to $0.49 \mathrm{~mm}$ & $+/-0.025 \mathrm{~mm}$ \\
\hline
\end{tabular}


Table $4 \quad$ Properties of piezoelectric ceramic APC-850 (www.americanpiezo.com)

\begin{tabular}{|c|c|c|c|c|c|c|}
\hline Material: & 840 & 841 & 850 & 855 & 856 & 880 \\
\hline \multicolumn{7}{|c|}{ Relative Dielectric Constant } \\
\hline$\varepsilon_{r}$ & 1250 & 1350 & 1750 & 3300 & 4100 & 1000 \\
\hline \multicolumn{7}{|c|}{ Dielectric Dissipation Factor (Dielectric Loss (\%)* } \\
\hline $\tan 8$ & 0.4 & 0.35 & 1.4 & 1.3 & 2.7 & 0.35 \\
\hline \multicolumn{7}{|l|}{ Curie Point $\left({ }^{\circ} \mathrm{C}\right)^{\star \star}$} \\
\hline $\mathrm{T}_{\mathrm{c}}$ & 325 & 320 & 360 & 250 & 150 & 310 \\
\hline \multicolumn{7}{|c|}{ Electromechanical Coupling Factor (\%) } \\
\hline $\mathrm{k}_{\mathrm{p}}$ & 0.59 & 0.60 & 0.63 & 0.68 & 0.65 & 0.50 \\
\hline$k_{33}$ & 0.72 & 0.68 & 0.72 & 0.76 & 0.73 & 0.62 \\
\hline $\mathrm{k}_{31}$ & 0.35 & 0.33 & 0.36 & 0.40 & 0.36 & 0.30 \\
\hline $\mathrm{k}_{15}$ & 0.70 & 0.67 & 0.68 & 0.66 & 0.65 & 0.55 \\
\hline \multicolumn{7}{|c|}{ Piezoelectric Charge Constant $\left(10^{-12} \mathrm{C} / \mathrm{N}\right.$ or $\left.10^{-12} \mathrm{~m} / \mathrm{V}\right)$} \\
\hline$d_{33}$ & 290 & 300 & 400 & 630 & 620 & 215 \\
\hline$-d_{31}$ & 125 & 109 & 175 & 276 & 260 & 95 \\
\hline $\mathrm{d}_{15}$ & 480 & 450 & 590 & 720 & 710 & 330 \\
\hline \multicolumn{7}{|c|}{ Piezoelectric Voltage Constant $\left(10^{-3} \mathrm{Vm} / \mathrm{N}\right.$ or $\left.10^{-3} \mathrm{~m}^{2} / \mathrm{C}\right)$} \\
\hline$g_{33}$ & 26.5 & 25.5 & 26 & 21.0 & 18.5 & 25 \\
\hline$-g_{31}$ & 11 & 10.5 & 12.4 & 9.0 & 8.1 & 10 \\
\hline$g_{15}$ & 38 & 35 & 36 & 27 & 25 & 28 \\
\hline \multicolumn{7}{|c|}{ Young's Modulus $\left(10^{10} \mathrm{~N} / \mathrm{m}^{2}\right)$} \\
\hline $\mathrm{Y}^{\mathrm{E}}{ }_{11}$ & 8 & 7.6 & 6.3 & 5.9 & 5.8 & 9 \\
\hline $\mathrm{Y}_{33}$ & 6.8 & 6.3 & 5.4 & 5.1 & 4.5 & 7.2 \\
\hline \multicolumn{7}{|c|}{ Frequency Constants $(\mathrm{Hz} * \mathrm{~m}$ or $\mathrm{m} / \mathrm{s})$} \\
\hline $\mathrm{N}_{\mathrm{L}}$ (longitudinal) & 1524 & 1700 & 1500 & 1390 & --- & 1725 \\
\hline $\mathrm{N}_{\mathrm{T}}$ (thickness) & 2005 & 2005 & 2032 & 2079 & 1980 & 2110 \\
\hline $\mathrm{N}_{\mathrm{P}}$ (planar) & 2130 & 2055 & 1980 & 1920 & --- & 2120 \\
\hline \multicolumn{7}{|l|}{ Density $\left(\mathrm{g} / \mathrm{cm}^{3}\right)$} \\
\hline$\rho$ & 7.6 & 7.6 & 7.7 & 7.7 & 7.5 & 7.6 \\
\hline \multicolumn{7}{|c|}{ Mechanical Quality Factor } \\
\hline $\mathrm{Q}_{\mathrm{m}}$ & 500 & 1400 & 80 & 65 & 72 & 1000 \\
\hline
\end{tabular}

All values nominal; measurements made 24 hours after polarization. Maximum voltage:5-7 VAC /mil for 850,855,856 VDC 2X. 9-11 VAC /mil for 840,841,880 VDC 2X.

*At $1 \mathrm{kHz}$, low field.

**Maximum operating temperature = Curie point $/ 2$

\subsubsection{Geometric Measurements}

Twenty-five nominally identical APC-850 wafers were measured with precision instrumentation consisting of Mitutoyo Corp. CD - 6" CS digital caliper (0.01-mm precision) and Mitutoyo Corp. MCD - 1" CE digital micrometer (0.001-mm precision). Length, width, and thickness were measured and recorded. Good agreement with the theoretical normal distribution (Gauss law) was observed. Mean and standard deviation values for length/width and thickness were 6.9478 $\mathrm{mm}, \pm 0.5 \%$, and $0.2239 \mathrm{~mm}, \pm 1.4 \%$, respectively. 


\subsubsection{Electrical Measurements}

Electrical capacitance was measured with a BK Precision ${ }^{\circledR}$ Tool Kit ${ }^{\mathrm{TM}} 27040$ digital multi-meter with a resolution of $1 \mathrm{pF}$. Capacitance measurements were selected as an in-process quality check to be applied during each step of sensor development and also during the sensor installation process.

\subsubsection{Direct Capacitance Tests Using Metallic Ground Plate}

Capacitance of the basic PWAS was measured directly by putting the square PWAS on a flat metallic ground plate. The negative probe was connected to the plate in a semi-permanent fashion (hole, bolt + nut + washer, short multifilament lead, alligator clip), and the top of the square PWAS was touched with the positive probe. Then, data was taken when the tester readings had converged to a stable value. At least 6 readings were recorded and the average was taken. The process was iteratively improved until consistent results were obtained. At least 6 readings were taken to a form statistical set of data. Mean and standard deviation values were $3.276 \mathrm{nF}, \pm 3.8 \%$. While this method has clear advantages, it also has the shortcoming that instability in electrical readings may occur due to lack of a firm electrical connection through mechanical clamping of the parts in contact.
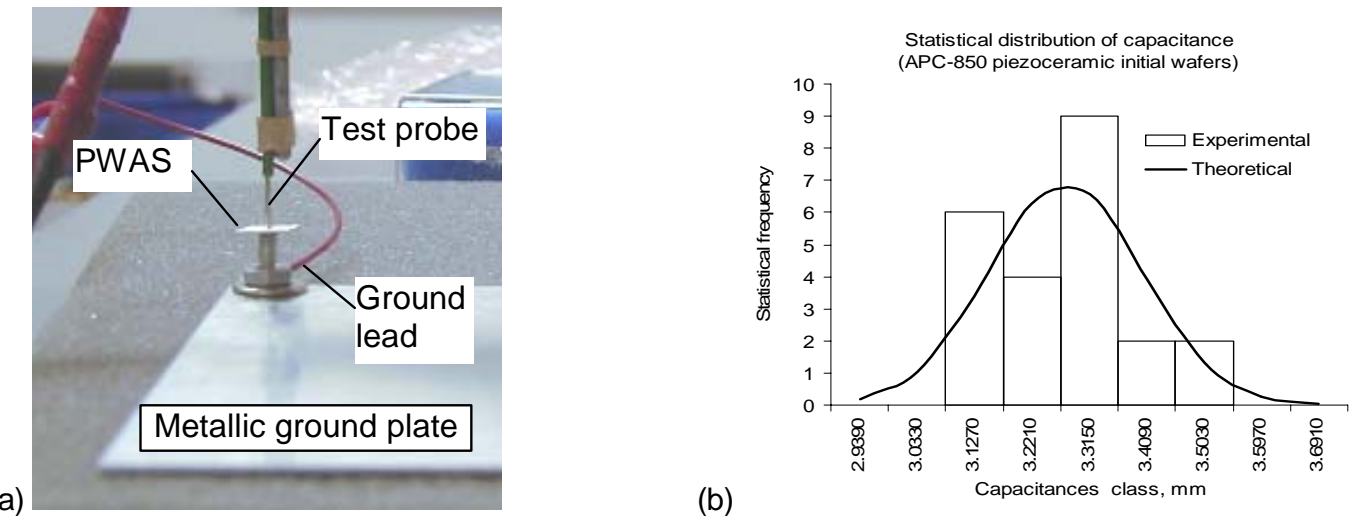

Figure 3 (a) In process quality check equipment: aluminum ground plate with metallic bolt head for measurement of PWAS capacitance and E/M impedance and admittance spectra; (b) Statistical distribution of APC-850 piezoceramic 7 mm square PWAS capacitance: as measured on metallic ground plate.

Table 5 shows the thickness, diameter, length, area, and the capacitance $-C=\varepsilon_{r} \varepsilon_{o} \frac{A}{t}$, where: he relative dielectric constant $\varepsilon_{r}=1750$, and the permittivity of free space $\varepsilon_{o}=8.85 \mathrm{E}-12(\mathrm{~F} / \mathrm{m})$

Table 5 Theoretical free capacitance for $7 \mathrm{~mm}$ and $10 \mathrm{~mm}$ round and square PWAS

\begin{tabular}{|l|c|c|c|c|}
\hline & Thickness & $\begin{array}{c}\text { Dia/length } \\
(\mathrm{mm})\end{array}$ & $\begin{array}{c}\text { Area } \\
\left(\mathrm{mm}^{2}\right)\end{array}$ & $\begin{array}{c}\text { Capacitance } \\
(\mathrm{nF})\end{array}$ \\
\hline Round $7 \mathrm{~mm}$ & 0.2 & 7 & 38.5 & 2.98 \\
\hline Round $10 \mathrm{~mm}$ & 0.2 & 10 & 78.5 & 6.08 \\
\hline Square $7 \mathrm{~mm}$ & 0.2 & 7 & 49 & 3.79 \\
\hline Square $10 \mathrm{~mm}$ & 0.2 & 10 & 100 & 7.74 \\
\hline
\end{tabular}

\subsubsection{Measurements of PWAS Intrinsic E/M Impedance and Admittance Spectra}

The intrinsic E/M impedance and admittance spectra of the PWAS, before being attached to the structure, were measured with the HP 4194A Impedance Phase-Gain Analyzer. We used a metallic plate with a lead connected at one corner. The PWAS was centered on the bold head and held in place with the probe tip. Thus, center clamping conditions were simulated, and the wafer could perform free vibrations while being tested. 

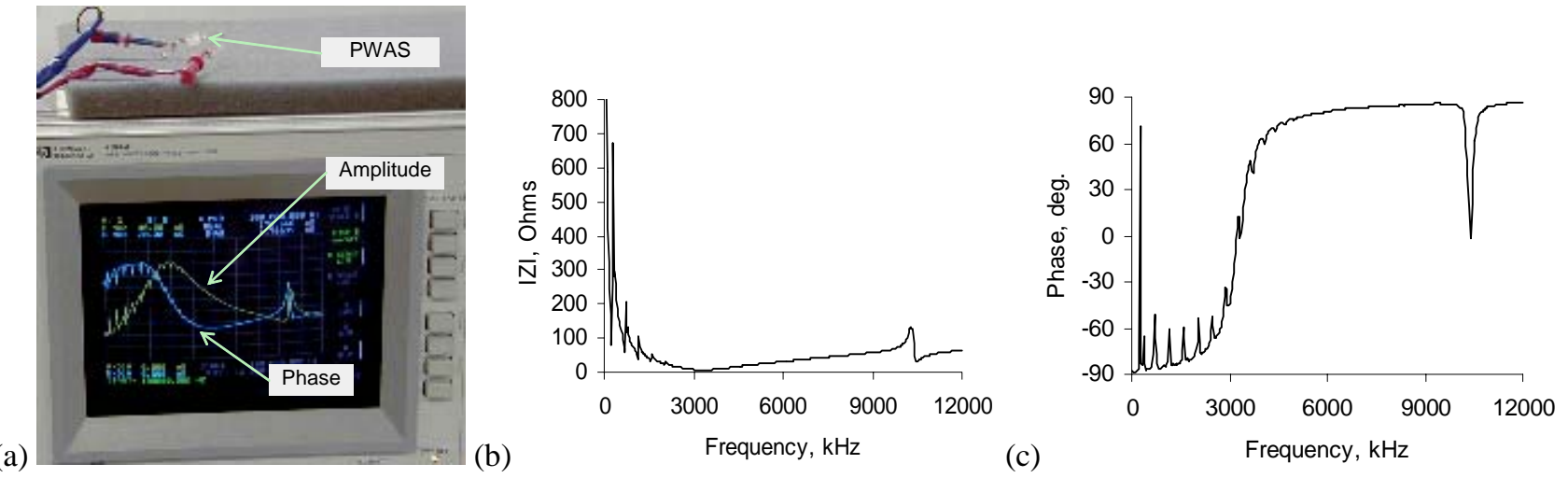

Figure 4 (a) Experimental set up for measuring the impedance and admittance characteristics of the PWAS with HP 4194A Impedance Phase-Gain Analyzer. Impedance characteristic of a free-free free $7 \mathrm{~mm}$ square PWAS: (b) amplitude of impedance; (c) phase of impedance;

To obtain the intrinsic E/M impedance and admittance spectra, the PWAS were tested in the $100 \mathrm{~Hz}-12 \mathrm{MHz}$ frequency range using the HP 4194A Impedance Analyzer. The data was collected through the GPIB interface and processed in MS Excel. Typical impedance frequency spectra are given Figure 4. The PWAS resonance frequencies were identified from the E/M admittance spectra. It was found that since the length and the width of the PWAS are nearly identical, the corresponding lengthwise and widthwise frequencies are coalescent, forming twin-peaks of in-plane vibration resonances. The first, second, and third in-plane resonance frequencies, as well as the out-of-plane (thickness) resonance (which is at much higher frequency) were identified and recorded. Also recorded were the values of the corresponding resonance peaks. Statistical distributions of the resonance frequencies and resonance amplitudes are given in Figure 5. Mean values of $251 \mathrm{kHz}$ and $67.152 \mathrm{mS}$, and standard deviations of $\pm 1.2 \%$ and $\pm 21 \%$, respectively, were obtained. These results proved that the basic APC-850 piezoelectric wafers had acceptable quality with a narrow dispersion band in resonance frequency.
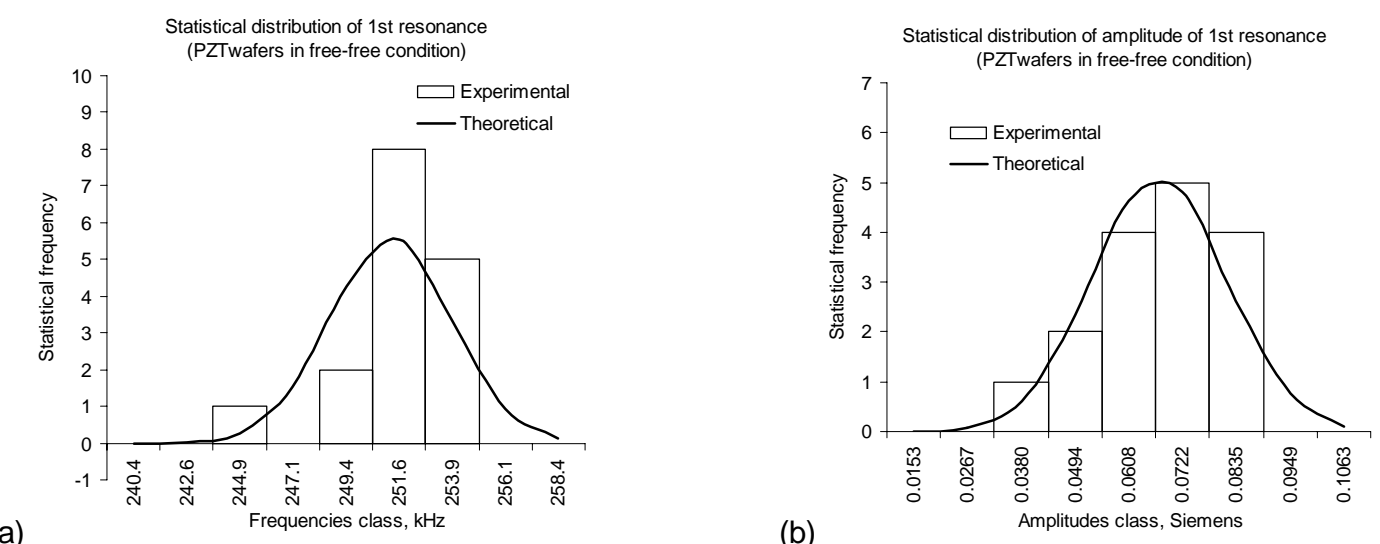

Figure 5 Statistical distribution of (a) $1^{\text {st }}$ resonance frequencies and (b) admittance amplitudes on $1^{\text {st }}$ resonance of APC-850 piezoceramic wafers.

\section{5. $\quad$ Existing Attached PWAS Specifications}

\subsection{1. $\quad 7 \mathrm{~mm}$ Square PWAS}

There are a total of nine PWAS in the array. The nine PWAS were installed in the center of a 4' X 4' sheet of 2024-T3 aluminum. The sheet of aluminum had the thickness to $1 \mathrm{~mm}$. Table 6 shows the capacitance for the $7 \mathrm{~mm}$ square PWAS array on Plate \# 1. The magnitude and phase of impedance of the PWAS are shown in Figure 6. All of the graphs for the PWAS are similar except for Sensor 3. This could be due to the bonding of PWAS on the plate. Table 7 displays the max and min values for the magnitude of the impedance and admittance of the PWAS. The max and min 
values of the PWAS are close and this shows that the PWAS has some type of consistency.

Table $6 \quad$ Capacitance for PWAS on Plate \#1

\begin{tabular}{|l|l|l|l|l|l|l|l|l|l|l|}
\hline Plate \#1 - $7 \mathrm{~mm}$ Square PWAS & 1 & 2 & 3 & 4 & 5 & 6 & 7 & 8 & 9 & Average \\
\hline Capacitance(nF)(wired PWAS) & 2.85 & 2.88 & 2.91 & 2.84 & 2.69 & 2.76 & 2.8 & 2.7 & 2.97 & 2.82 \\
\hline
\end{tabular}

(a)

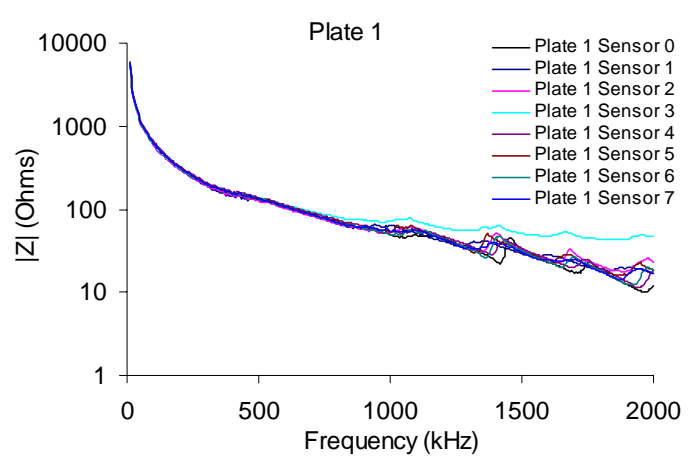

(b)

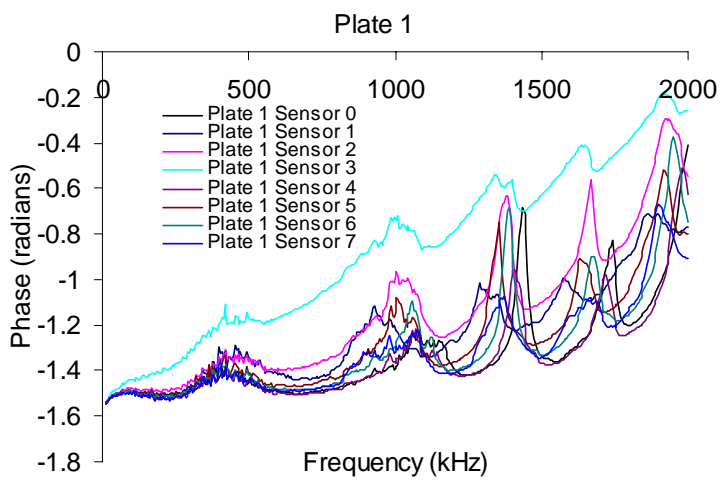

Figure 6 (a) Magnitude and (b) Phase of Impedance for $7 \mathrm{~mm}$ Square PWAS on Plate 1

Table $7 \quad$ Max and Min values for the Magnitude of the Impedance and Admittance of the $7 \mathrm{~mm}$ Square PWAS on Plate \#1

\begin{tabular}{|c|c|c|c|c|}
\hline \multicolumn{5}{|c|}{ Plate \#1 - 7 mm Square PWAS } \\
\hline \multirow{2}{*}{ PWAS \# } & \multicolumn{2}{|c|}{$|\mathrm{Z}|$ (Ohms) } & \multicolumn{2}{|c|}{$|\mathrm{Y}|$ (Siemens) } \\
\cline { 2 - 5 } & Max & Min & Max & Min \\
\hline 1 & 5580 & 9.98 & 0.100 & 0 \\
\hline 2 & 5540 & 16.88 & 0.058 & 0 \\
\hline 3 & 5480 & 17.92 & 0.056 & 0 \\
\hline 4 & 5590 & 42.9 & 0.025 & 0 \\
\hline 5 & 5970 & 11.26 & 0.089 & 0 \\
\hline 6 & 5740 & 16.19 & 0.062 & 0 \\
\hline 7 & 5700 & 12.39 & 0.081 & 0 \\
\hline 8 & 5760 & 14.28 & 0.070 & 0 \\
\hline 9 & 5370 & 9.63 & 0.104 & 0 \\
\hline $1-9$ & 5970 & 9.63 & 0.104 & 0 \\
\hline
\end{tabular}

\subsubsection{7 mm Diameter PWAS}

There are a total of eight PWAS in the array. The eight PWAS were installed in the center of a 4' X 4' sheet of 2024-T3 aluminum. The sheet of aluminum had the thickness to $1 \mathrm{~mm}$. Table 8 shows the capacitance for the $7 \mathrm{~mm}$ diameter PWAS array on Plate \# 3. The magnitude and phase of impedance of the PWAS are shown in Figure 7. All of the graphs for the PWAS are similar except for Sensor 4. This could be due to the bonding of PWAS on the plate. Table 9 displays the max and min values for the magnitude of the impedance and admittance of the PWAS. The max and min values of the PWAS are close and this shows that the PWAS has some type of consistency.

Table 8

Capacitance for PWAS on Plate \#3

\begin{tabular}{|l|c|c|c|c|c|c|c|c|c|c|}
\hline Plate \#3 - 7 mm dia PWAS & 1 & 2 & 3 & 4 & 5 & 6 & 7 & 8 & 9 & Average \\
\hline Capacitance(nF)(wired PWAS) & 2.67 & 2.71 & 2.68 & 2.65 & 2.63 & 2.68 & 2.71 & 2.71 & NA & 2.68 \\
\hline
\end{tabular}


(a)

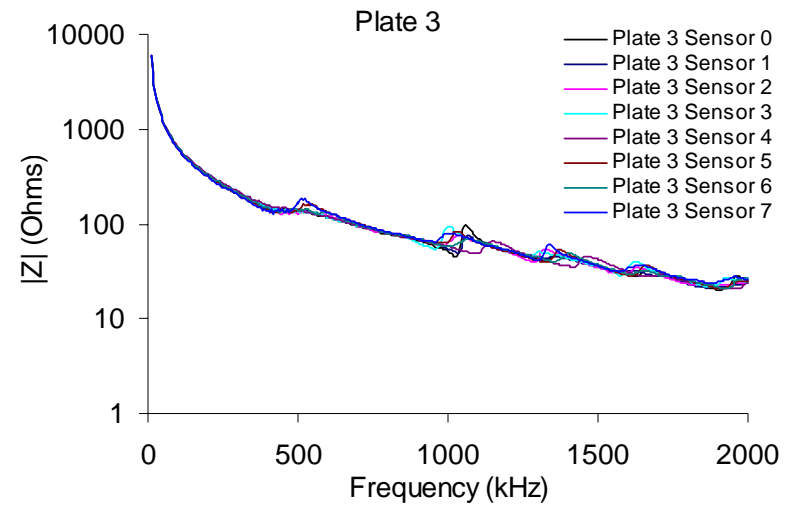

Figure 7 (a) Magnitude of Impedance for $7 \mathrm{~mm}$ Diameter PWAS on Plate 3; (b)Phase of Impedance for $7 \mathrm{~mm}$ Diameter PWAS on Plate 3

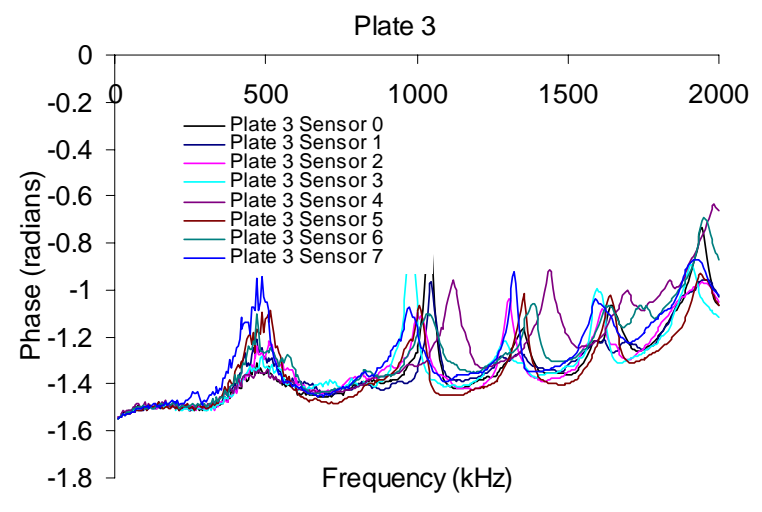

Table 9 Max and Min values for the Magnitude of the Impedance and Admittance of the $7 \mathrm{~mm}$ Diameter PWAS on Plate \#3

\begin{tabular}{|c|c|c|c|c|}
\hline \multicolumn{5}{|c|}{ Plate \#3 - 7 mm diameter PWAS } \\
\hline \multirow{2}{*}{ PWAS \# } & \multicolumn{2}{|c|}{$|\mathrm{Z}|$ (Ohms) } & \multicolumn{2}{|c|}{$|\mathrm{Y}|$ (Siemens) } \\
\cline { 2 - 5 } & Max & Min & Max & Min \\
\hline 1 & 6000 & 20.2 & 0.048 & 0 \\
\hline 2 & 5950 & 21.4 & 0.047 & 0 \\
\hline 3 & 5960 & 22.6 & 0.045 & 0 \\
\hline 4 & 6100 & 21.9 & 0.045 & 0 \\
\hline 5 & 6080 & 20.6 & 0.054 & 0 \\
\hline 6 & 5980 & 20.6 & 0.048 & 0 \\
\hline 7 & 6000 & 20.9 & 0.048 & 0 \\
\hline 8 & 5910 & 23.3 & 0.043 & 0 \\
\hline $1-8$ & 6100 & 20.2 & 0.054 & 0 \\
\hline
\end{tabular}

\subsection{Desired PWAS Specifications}

The desired PWAS is dimension are a $10 \mathrm{~mm}$ square PWAS and a $10 \mathrm{~mm}$ diameter PWAS. The capacitance, impedance, and admittance values for these PWAS could be approximated using the area rule from the values for the 7mm PWAS.

\section{STRUCTURAL HEALTH MONITIORING OVERVIEW}

The purpose to this section is to describe the PWAS and equipment setup and specifications. Figure 8 shows the PWAS phase array installed on an aluminum plate. Figure 8d shows the whole measurement equipments setup. The PWAS array is connected to the switch box with an 8-pin ribbon bus; the function generator and oscilloscope are connected to the switch box with coaxial cables. The switch box is connected to the parallel port of the control PC to receive digit control signals. 

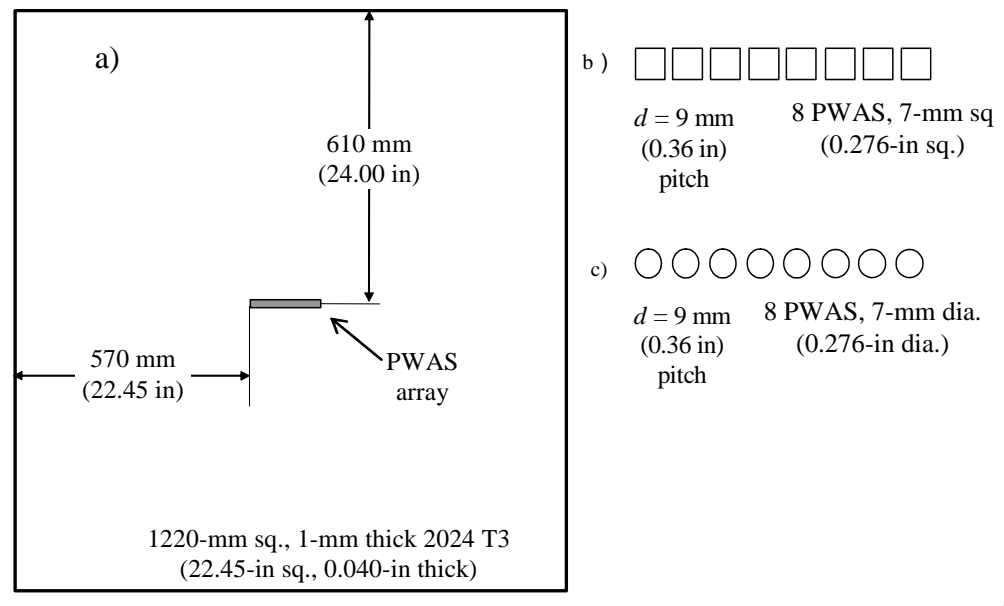

(22.45-in sq., 0.040 -in thick)

Figure 8 Specimen aluminum plate and the PWAS array: a) 4-ft square plate with 8-element PWAS array at its center; b) details of the 8-element PWAS array with 7-mm square PWAS; c) details of the 8-element PWAS array with 7-mm diameter PWAS; d) PWAS Phased Array Experimental setup

\section{EXISTING EQUIPMENT:}

Figure 8d shows a layout of the existing equipment. The sensing equipment used was the Digital Phosphor Oscilloscopes - Tektronix TDS210 which has a bandwidth of $60 \mathrm{MHz}$; sample rate of 1GS/s; record length of 2500 point buffer (2.5 k); two channels; and an averaging of 4, 16, 64, and 128. The excitation equipment used was an Agilent $33120 \mathrm{~A}$ Function/Arbitrary Waveform Generator with a nominal $V_{p p}=10 \mathrm{~V}$ and up to $20 V_{p p}$ at low frequencies. Figure 9a shows an experiment done with the wave generation. The graph shows that the frequency decays to $10 V_{p p}$ at $2,000 \mathrm{kHz}$. The round-robin signal collection was done by the ASCU-PWAS Switch Box, which has 8 Channels.

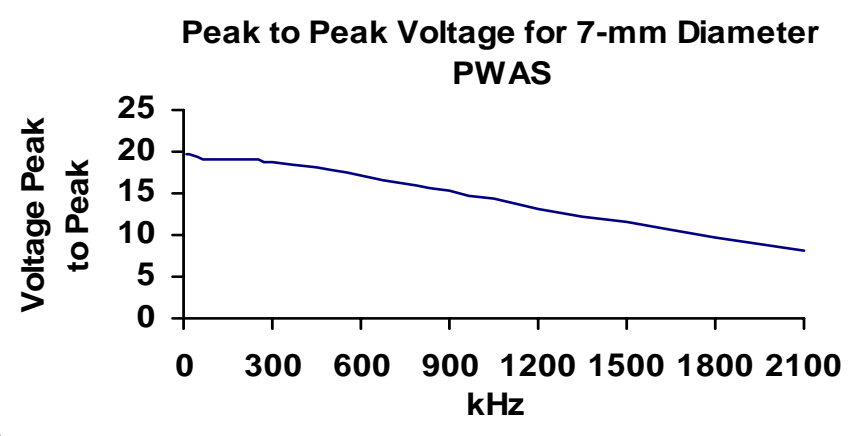

(a)

$$
\mathrm{kHz}
$$

Figure 9 (a) Shows that as frequency increases the voltage peak to peak decreases(b) Signal shape with a Hanning Window from the waveform generator. The frequency is $100 \mathrm{kHz}$, the number of counts is three, and the amplitude is 1 . 


\section{DESIRED EQUIPMENT:}

The desired sensing equipment is the Digital Phosphor Oscilloscope - Tektronix TDS5034B which has a bandwidth of $350 \mathrm{MHz}$; sample rate of 5GS/s; a record Length of an 8M buffer; and four channels. For the excitation equipment, it is desired to have excitation equipment that will cover the complete voltage range of the PWAS, which is $V(t)=45 \pm 75 \mathrm{~V}$ up to $2,000 \mathrm{kHz}$. We desire to have equipment that can measure a $\mathrm{V}_{\mathrm{pp}}$ equal to $150 \mathrm{~V}$ with a $\mathrm{V}_{\mathrm{DC}}$ equal to $45 \mathrm{~V}$ on a $10 \mathrm{~mm}$ square PWAS. $\mathrm{V}_{\mathrm{pp}}$ count will be over a frequency range of $10 \mathrm{kHz}$ to $2,000 \mathrm{kHz}$. At present, we are adding to the existing equipment a signal amplifier - the Krohn-Hite 7602 which has a dc to $1 \mathrm{MHz}$ Frequency Range; voltage gain of $0 \mathrm{~dB}$ to $42 \mathrm{~dB}$ in three ranges - $0 \mathrm{~dB}$ to $14 \mathrm{~dB}, 14 \mathrm{~dB}$ to $28 \mathrm{~dB}, 28 \mathrm{~dB}$ to $42 \mathrm{~dB}$; continuously variable between ranges; the stability of $<0.001 \mathrm{~dB}$ change for a $10 \%$ change in line voltage; and a harmonic distortion of $<0.01 \%$ to $5 \mathrm{kHz}$ and $175 \mathrm{~V}$ peak output, $<0.05 \% 200 \mathrm{~V}$ peak output; $<0.3 \%$ to $100 \mathrm{kHz}$. The desired round-robin signal collection is a 16 and 32 Channel ASCU-PWAS Switch Box.

\section{AUTOMATIC SIGNAL COLLECTION UNIT FOR PWAS STRUCTURAL HEALTH MONITORING (ASCU-PWAS)}

An automatic signal switch is necessary to send the excitation signals to PWAS and acquire the response signal from another PWAS. Such a program-controlled switch can quickly and precisely execute the data collection in a way which is more efficient and reliable than the manual switching operations. The automation of data collection consists of two parts: the hardware part of auto signal switch box and the corresponding software part of PC control program. In this method, digit control signals are generated by the PC software and sent to the switch box through the parallel port. According to the control signals form the parallel port, the switch box will connect the function generator and oscilloscope each to one sensor (these two sensor can be the same) of the PWAS array respectively. Thus, one signal measurement route is constructed, the excitation signal is transmitted to the PWAS array and echo signals are received by the oscilloscope. With this method, the measurement loops are performed automatically under the control of the PC software.

\subsection{Existing Switch Box}

ASCU - PWAS

8 - Channels

Round-Robin Excitation: One channel is excited and all the other channels are collected including the exciter.

(a)

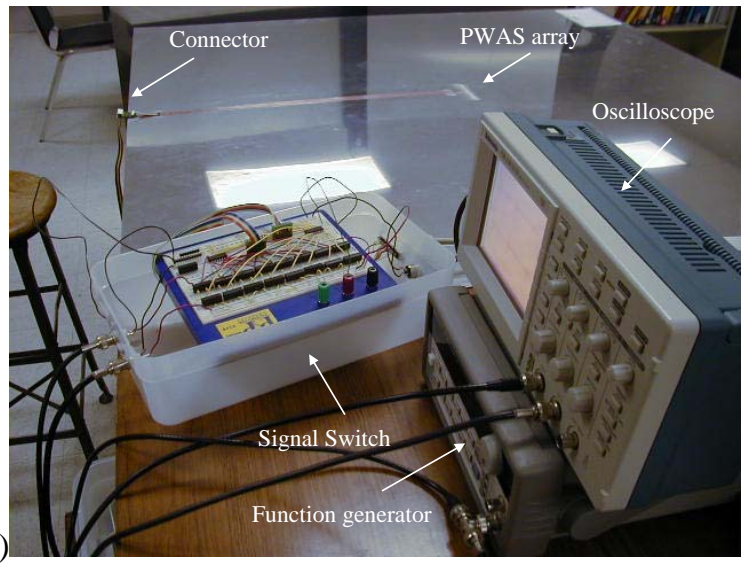

(b)

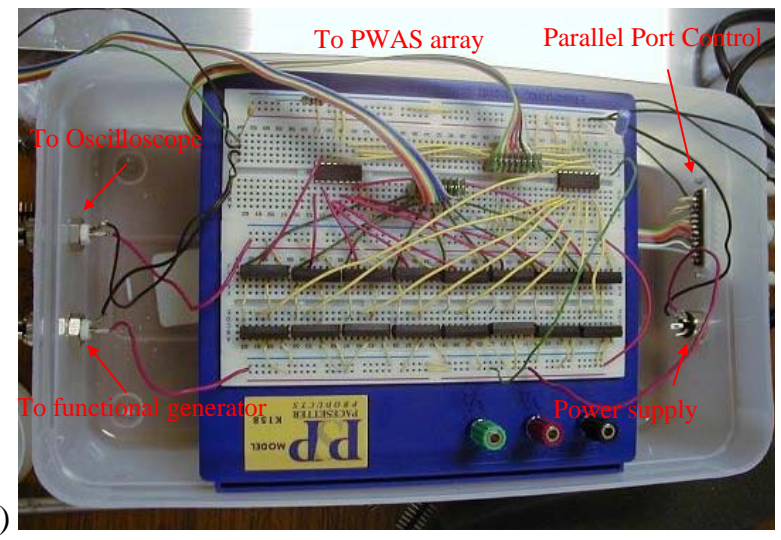

Figure 10 DAQ system setup: picture of the specimen, the auto signal switch, the oscilloscope and the function generator. (b) Auto signal switch 


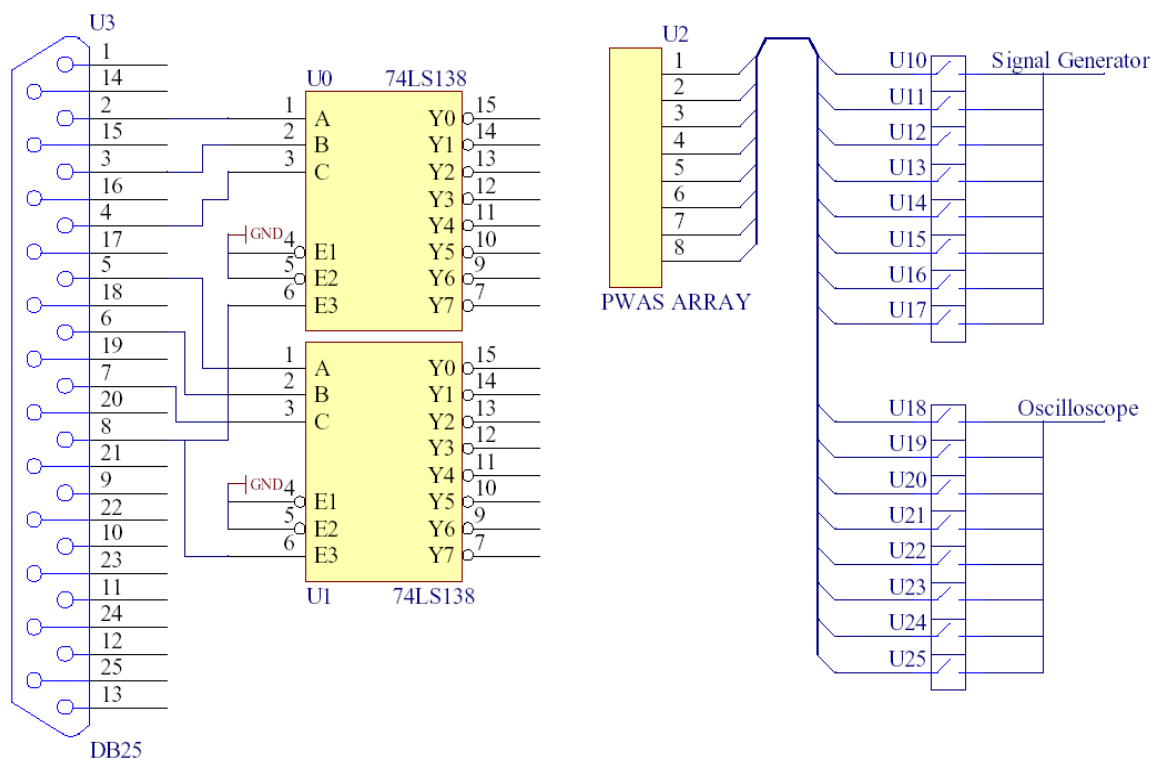

(a)

Figure $11 \quad$ (a) Auto signal switch circuit diagram,

\section{2. $\quad$ Desired Switch Box}

16 and 32 Channels

Requirement: The switch box shall not modify the excitation and the sensed signs.

Note: LAMSS experience with ASCU-PWAS (inventing disclosure \# 00433 of May 2004) indicated the electronic switching gave unsatisfactory results for the tone bursted excitation because unwanted noise was introduced. LAMSS has resolved this issue by using reed relays. The new switch box has 16 channels as shown in Figure 12. This will allow for larger PWAS Arrays and more data collection.

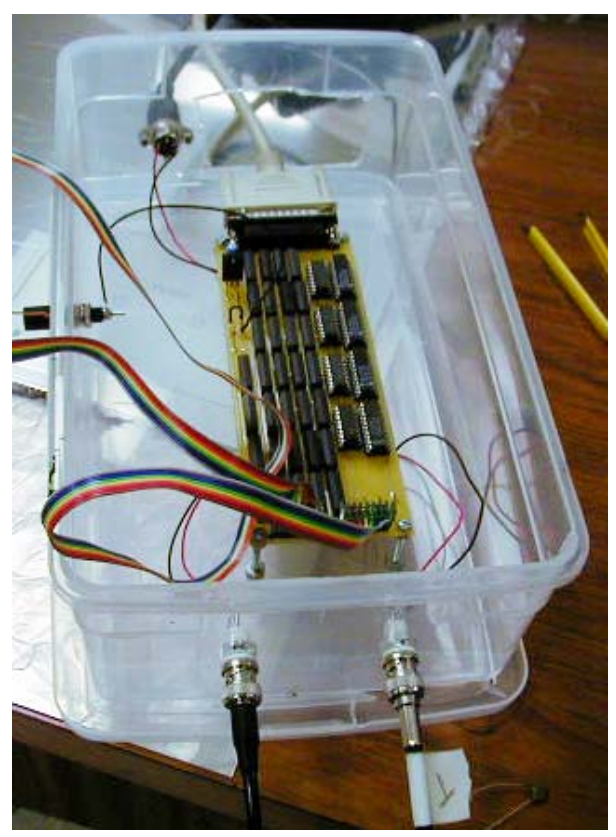

Figure 12 - 16 Channel PWAS Switch Box 


\section{CONCLUSIONS}

This paper showed the work performed in the development of specification for an integrated electronic system for PWAS. Studying the PWAS' material properties, dimensions, and electrical characteristics will help in designing and choosing a PWAS specification that will create the best desired results. By examining the two boundary conditions of the PWAS (free and attached), the behavior and consistency of the PWAS was observed and it could be noted the PWAS behaves similarly.

The electronic-equipment specifications were chosen to optimum performance from the PWAS, i.e., maximize the coupling with the structure and obtain large-amplitude Lamb wave transmission and reception. The current equipment doesn't fully exploit the PWAS capabilities and options for new equipment were explored to offer the same PWAS performance as the existing lab equipment, but be of a lower volume/weight/cost. The latter category refers to advanced electronic equipment that will exploit the full potential of PWAS transducers while being of lower volume/weight/cost than the lab equipment.

\section{ACKNOWLEDGMENTS}

The financial support of National Science Foundation award \# CMS 0408578, Dr. Shih Chi Liu, program director, and Air Force Office of Scientific Research grant \# FA9550-04-0085, Capt. Clark Allred, PhD, program manager are gratefully acknowledged.

\section{REFERENCES}

1 Crawley E. F.; Anderson, E. H. (1990) "Detailed Models of Piezoceramic Actuation of Beams", Journal of Intelligent Material Systems and Structures, Vol. 1, No. 1, January 1990, pp. 4-25

2 Dalton, R. P.; Cawley, P.; Lowe, M. J. (2001) "The Potential of Guided Waves for Monitoring Large Areas of Metallic Aircraft Fuselage Structure”, Journal of Nondestructive Evaluation, Vol. 20, pp. 29-45, 2001

3 Deutsch, W. A. K; Cheng, A.; Achenbach, J. D. (1999) "Focusing of Rayleigh Waves: Simulation and Experiments”, IEEE Transactions on Ultrasonics, Ferroelectrics, and Frequency Control, Vol. 46, No. 2, March 1999

4 Giurgiutiu, V.; Redmond, J.; Roach, D.; Rackow, K. (2000)“Active sensors for health monitoring of aging aerospace structures", Proceedings of the SPIE Conference on Smart Structures and Integrated Systems, Vol. 3985, pp. 294-305, Newport Beach, 2000

5 Giurgiutiu, V.; Zagrai, A. (2000) “Characterization of piezoelectric wafer active sensors”, Journal of Intelligent Material Systems and Structures, Vol. 11, pp. 959-976, 2000

6 Liu, T.; Veidt, M.; Kitipornchai, S. (2003) "Modeling the Input-output Behavior of Piezoelectric Structural Health Monitoring systems for Composites Plates”, Smart Materials and Structures, Vol. 12, pp. 836-844, 2003 